\title{
THE CO/PC ANALOGY IN COORDINATION CHEMISTRY AND CATALYSIS
}

\author{
Marjolaine Doux, Audrey Moores, Nicolas Mézailles, Louis Ricard, Yves Jean \\ and Pascal Le Floch*
}

Laboratoire « Hétéroéléments et Coordination » UMR CNRS 7653,

Ecole Polytechnique, 91128 Palaiseau Cedex, France

Tel: +33.1.69.33.45.70; Fax:+33.1.69.33.39.90; e-mail:lefloch@poly.polytechnique.fr

\begin{abstract}
This short account summarizes recent results obtained in the coordination chemistry of phosphinines and emphasizes their analogy with CO ligands. Reduced complexes can be easily assembled through the reaction of reduced 2,2'-biphosphinine dianions with transition metal fragments. Theoretical calculations were performed to establish the oxidation state of the metal in these complexes. Though many reduced complexes are available, phosphinines proved to be too sensitive toward nucleophiles to be used as efficient ligands in most catalytic processes. However, the high electrophilicity of the phosphorus atom can be exploited to synthesize phosphacylohexadienyl anions which exhibit a surprising coordination chemistry. When phosphino sulfide groups are incorporated as ancillary tridentate anionic SPS ligands can be easily produced. These ligands can bind different transition metal fragments such as $\mathrm{M}-\mathrm{X}(\mathrm{M}=$ group 10 metal, $\mathrm{X}=$ halogen $), \mathrm{Rh}-\mathrm{L}(\mathrm{L}=2$ electron donor ligand), $\mathrm{Cu}-\mathrm{X}$ and $\mathrm{Au}-\mathrm{X}$ ( $\mathrm{X}=$ halogen). Palladium(II) complexes proved to be active catalyst in the Miyaura crosscoupling reaction. Bidentate anionic PS ligands were also synthesized following a similar approach. Their Pd(II) (allyl) derivatives showed a very good activity in the Suzuki catalyzed cross-coupling process that allows the synthesis of biphenyl derivatives through the reaction of phenylboronic acid with bromoarenes.
\end{abstract}

Keywords: Reduction, Catalysis, Complexes, Phosphorus Heterocycles, Macrocycles.

\section{Introduction}

The "analogy" that exists between carbon and phosphorus in their low coordinated states slowly emerged as a significant field of investigation in the modern chemistry of main group elements.[1] Though, this analogy is limited, it clearly appears that molecules which feature doubly and triply bonded carbon-phosphorus systems behave as their carbon 
counterparts in some organic transformations. Among numerous reactions, one of the most illustrative examples is given by the phospha-Wittig process that allows the formation of phosphaalkenes from the reaction phosphoranylidenphosphines $\mathbf{1}$ or their Horner-Emmons equivalents 2 with aldehydes (Scheme 1).[2]

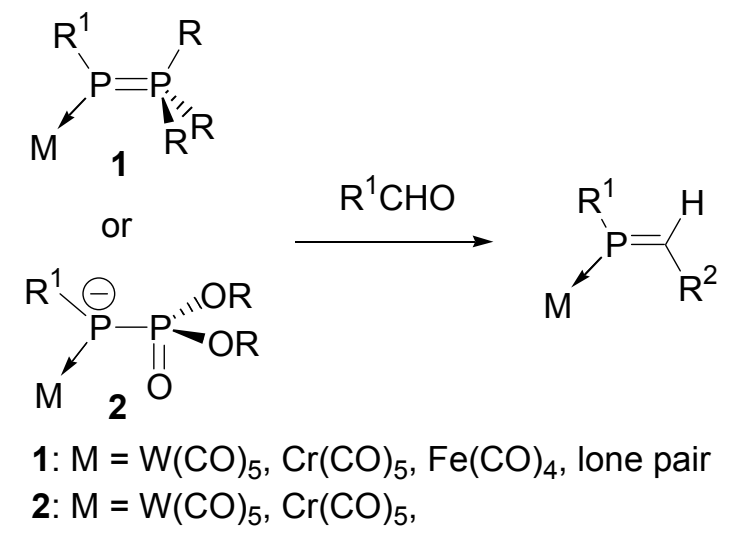

Scheme 1

The coordinative abilities of doubly or triply bonded systems also attracted a lot of attention since the discovery of the first phosphametallocene by Mathey and co-workers in 1975.[3] Since then, a considerable number of structures involving $\pi$-cordination of $\mathrm{P}=\mathrm{C}$ or $\mathrm{P} \equiv \mathrm{C}$ based systems have been reported and the domain rapidly expanded over the last ten years. Significant applications have also emerged especially in the area of homogeneous catalysis using complexes of aromatic phosphorus heterocycles such as phospholide anions.[4]

All these developments have found their origin in the complementary nature of carbon and phosphorus. Indeed, though at first sight phosphorus and carbon could be considered as very different elements with regards to their coordination states, both elements exhibit a remarkable combination of $\sigma$ and $\pi$ electronegativity. In fact, even if phosphorus is less electronegative than carbon, its $\pi$-electronegativity was shown to be more important than that of carbon especially when both elements are involved in a doubly or triply bonded system. This specific electronic situation implies that ligands incorporating $\mathrm{P}=\mathrm{C}$ systems present a close analogy with strong $\pi$-acceptor ligands such as carbonyl. Indeed, a simple molecular orbital diagram clearly shows that the LUMO of $\mathrm{P}=\mathrm{C}$ ligands is closer to that of $\mathrm{CO}$ than to that of classical $\mathrm{N}=\mathrm{C}$ based ligands. The main orbital coefficient is localized on the element which is directly bound to the metal. Obviously, $\mathrm{P}=\mathrm{C}$ systems exhibit a weaker $\pi$-accepting 
capacity since they essentially behave as monodimesional $\pi$-acceptor ligands (CO being considered as a bi-dimensional acceptor ligand because of its two available orthogonal $\pi^{*}$ orbitals) (Scheme 2).
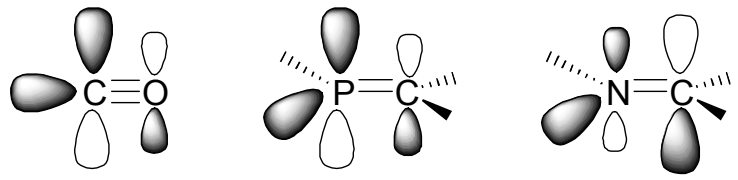

\section{Scheme 2}

\section{Results and discussion}

II.1) Reduced phosphinine transition metal complexes.

The analogy between $\mathrm{P}=\mathrm{C}$ systems and the carbonyl ligand has been partially explored and exploited so far. Pioneering works were achieved by the group of C. Elschenbroich and our group over the last decade. The discovery of the first homoleptic phosphinine complexes 3-5 (Ni,[5] Fe,[6] $\mathrm{Cr}[7])$ can really be considered as the starting point of this new facet of the "phosphorus-carbon analogy" (Scheme 3).

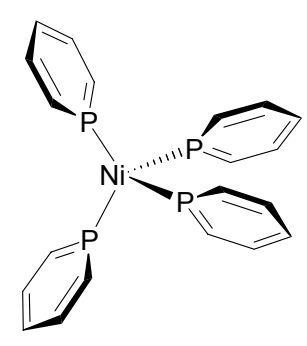

3

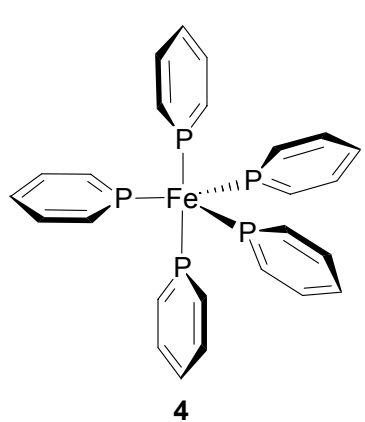

Scheme 3

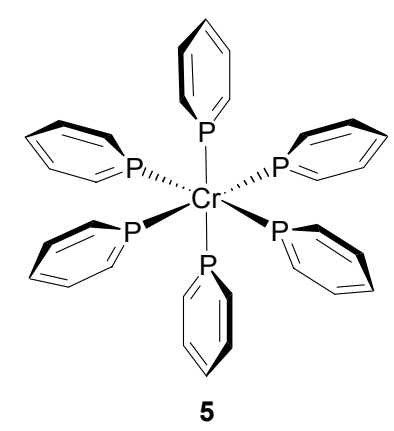

5

Reasoning that the strong $\pi$-accepting capacity of ligand such as phosphinines could be employed to stabilize transition metal complexes in unusual negative oxidation states, we early launched a program aimed at developing the use of bi and polydentate ligands featuring phosphinines as binding sites.[8] One of the most famous ligand to be reported in this series was the 2,2'-biphosphinines 6 whose synthesis was achieved in 1991.[9] As expected from theoretical and electrochemical data, these bidentate ligands markedly differ from their nitrogen counterparts, the ubiquitous 2,2'-bipyridines. Whereas 2,2'-bipyridine are well adapted to the coordination of electron-deficient metal centers, 2,2'-biphosphinines clearly favor the coordination of very electron rich or electron excessive metal centers like CO. 
Definitive evidences were given by the synthesis of a series of negatively charged biphosphinine complexes of different metals: dianionic homoleptic complexes of group 4 metals 7 were synthesized,[10] monoanionic complexes of group $7(\mathrm{M}=\mathrm{Mn}, \mathrm{Re}) \mathbf{8},[11]$ dianionic complexes of group $8(\mathrm{M}=\mathrm{Fe}, \mathrm{Ru})$ 9,[12] monoanionic complexes of group 9 metals $(\mathrm{M}=\mathrm{Co}, \mathrm{Rh}) \mathbf{1 0},[13]$ and a 19 electron nickel(-1) complex 11 was characterized by EPR spectroscopy (Scheme 4).[14] These complexes were obtained using one of the two following methods : a first conventional method proceeds via reduction of preformed complexes with the appropriate number of electrons; a second approach relies on the prior synthesis of a mono radical anion of the biphosphinine or its dianion followed by complexation.[15] This last method, which had already proven to be very efficient in the coordination chemistry of sulfur and nitrogen ligands, could be extended to phosphorus and provided an access to a wide range of reduced complexes.

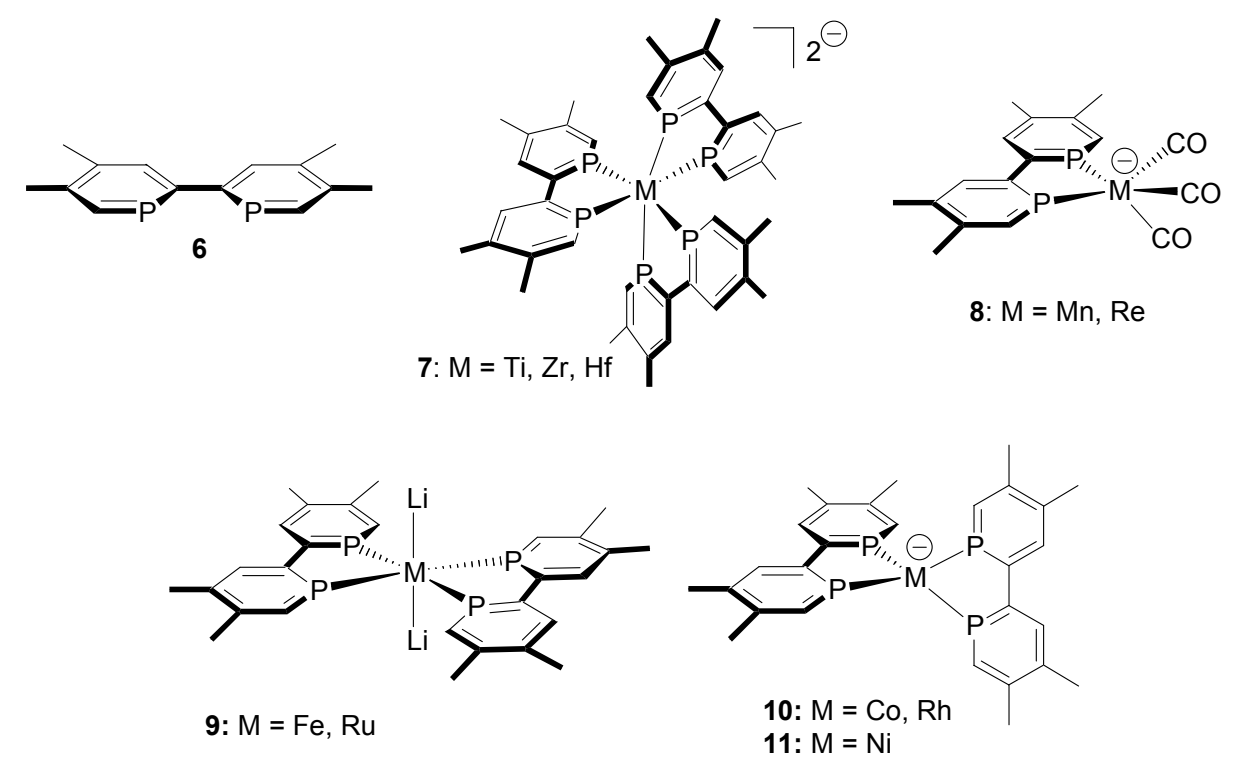

Scheme 4

The existence of such reduced species obviously raises the question of the formal oxidation state of the metal. An interesting example was provided by the synthesis of formally $\mathrm{d}^{10}$ monoanionic $(\mathrm{Co}(-1), \mathrm{Rh}(-1))$ and dianionic $(\mathrm{Ru}(-2))$ complexes with two biphosphinine ligands. Group 9 complexes adopt a distorted tetrahedral geometry in the solid state and group 8 complex adopts a square planar geometry. Recent theoretical studies [16] have shown that this particular situation is mainly due to the strong $\pi$-accepting properties of the biphosphinine ligands. It results in a small energy difference between the tetrahedral conformation (expected for a d ${ }^{10}-\mathrm{ML}_{4}$ complex) and the square planar conformation (expected for a d $\mathrm{d}^{8} \mathrm{ML}_{4}$ complex). 
In the absence of electrostatic interactions with the counter cation, a distorted tetrahedral geometry was actually found for the group 9 complexes. These calculations also revealed that the weak geometrical preference found for the tetrahedral conformation over the square planar one in the dianionic $\mathrm{Ru}(-2)$ complex $\left(3 \mathrm{kcal}^{\mathrm{mol}}{ }^{-1}\right)$ is reversed when interactions with cations occurred. In agreement with the experimental observation, calculations on the sodium complex actually show that the square planar complex $\mathbf{1 2}$ is more stable than its tetrahedral isomer 13, the computed energy difference being equal to $19.5 \mathrm{kcal} \mathrm{mol}^{-1}$ (Scheme 5).

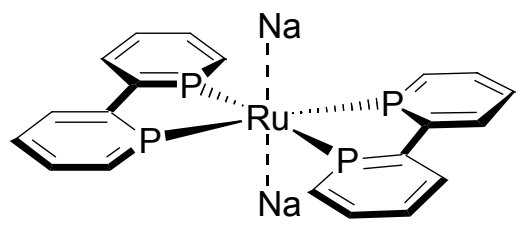

12

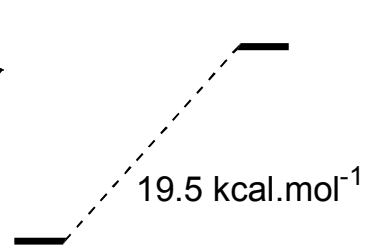

Scheme 5

Studies were not limited to biphosphinines and macrocyclic derivatives have also found interesting applications in the stabilization of electron rich metal centers. Thus, it has been shown that a silacalix-[4]-macrocycle could encapsulate a gold(I) center to afford complex 14. Most interestingly, reduction of this complex provided a monomeric gold(0) 15 complex which proved to be stable up to $243 \mathrm{~K}$. The fact that Au-CO decomposes at $70 \mathrm{~K}$ clearly suggests that phosphinine-based macrocycles can be considered as phosphorus equivalent of $\mathrm{CO}$ matrices.[17] Similarly, it has been showed that $\mathrm{Rh}(\mathrm{I})$ macrocyclic derivatives could be reversibly reduced to afford the corresponding $\mathrm{Rh}(0)$ and $\mathrm{Rh}(-1)$ complexes.[18]

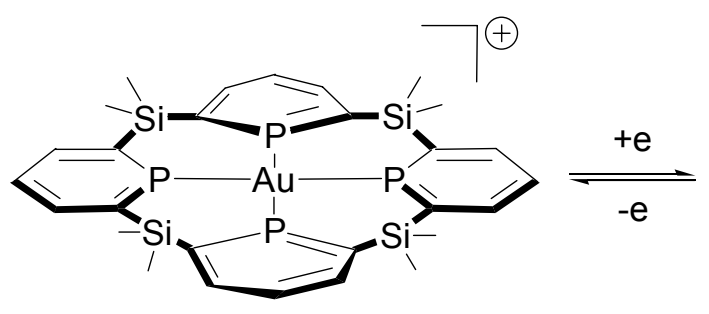

14

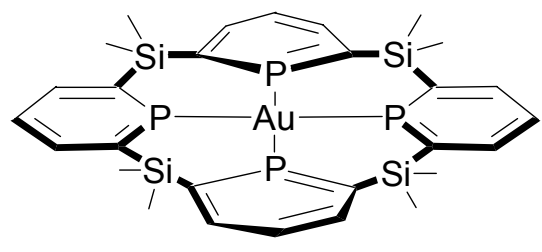

15

Scheme 6 


\section{II.2) Phosphinines in homogeneous catalysis.}

Homogeneous catalysis is another important field where phosphorus analogs of the carbonyl ligand may find interesting applications. Though low coordinated phosphorus ligands such as kinetically stabilized 1,4-phosphabutadienes [19] and phosphaferrocenes already proved to be valuable systems,[20] only a little is known about the use of phosphinines. The most significant report was made by the group of Breit in collaboration with BASF in the hydroformylation of olefins process. Functional derivatives of the 2,4,6 triphenylphosphinines such as $\mathbf{1 6}$ exhibited an interesting activity in the hydroformylation of styrene and cyclohexene.[21] Most importantly, in more drastic conditions, they also exhibit a significant activity in the hydroformylation of tetramethylethylene to afford 2,3dimethylbutanal through an isomerization process (Scheme 7)

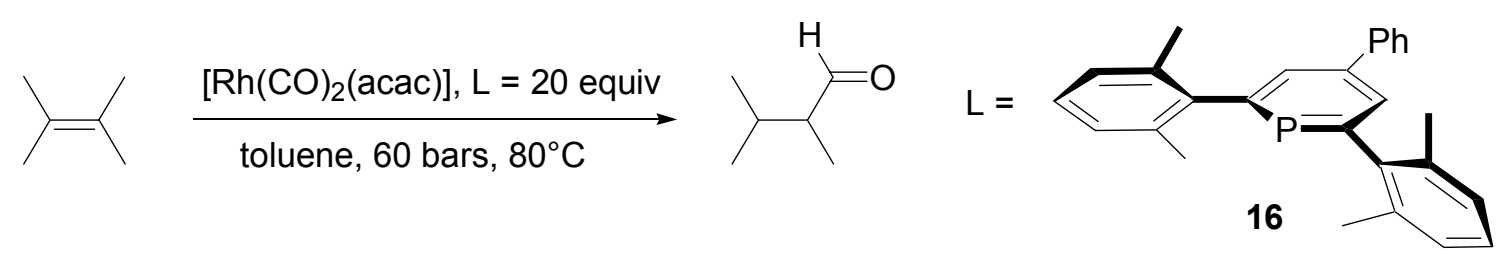

Scheme 7

Unfortunately, if we exclude their use as $\pi$-ligands in the iron catalyzed cyclotrimerization of alkynes and nitriles to give pyridines,[22] phosphinines, once bound to a metal center, proved to be too sensitive toward nucleophilic attacks (like $\mathrm{CO}$ based analogous complexes) to be considered as potential ligands in metal-catalyzed processes involving nucleophilic reagents or bases. A representative example is provided by the hydrolysis of a [Pt(biphosphinine)ClMe] complex 17 which occurs when a dichloromethane solution of the complex is exposed to the presence of traces of water to afford compound $\mathbf{1 8}$ (Scheme 8). Interestingly the addition occurs onto the ring which is trans to the less electron donating ligand.[23]

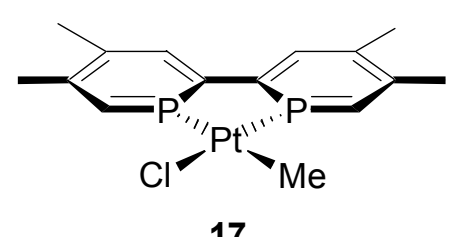

17

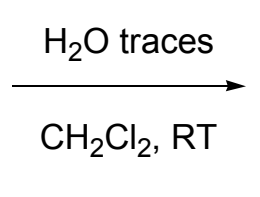

Scheme 8 


\section{II.3) Phosphacyclohexadienyl anions and their related ligands.}

Exploiting the high electrophilicity of the phosphorus atom allowed us to circumvent this limitation. Thus phosphacyclohexadienyl anions $\mathbf{1 9}$ which are readily obtained through the reaction of nucleophiles with phosphinines exhibit a surprising reactivity towards metal fragments allowing the synthesis of unusual complexes. Four lithium complexes of these anions, such as complex 20, were characterized by X-ray crystallography.[24] When no cryptand is used, coordination of the lithium occurs through the $\pi$-system of the ring. In good agreement with this result, DFT calculations showed the negative charge to be mostly localized on the $\alpha$-carbon atoms of these anions. An analysis of the charge distribution revealed that the electronic structure of these anions is closer to that of classical pentadienyl anions than to that of their analogs, the cyclohexadienyl anions. Interestingly a Natural Bond Orbital Analysis (NBO) and the analysis of Wyberg bond indices revealed that no delocalization takes place between the carbocyclic part of the ring and the phosphorus atom. In such systems, the hydridization of the phosphorus atom lone pair is close to that of classical tertiary phosphines (Scheme 9).[24]
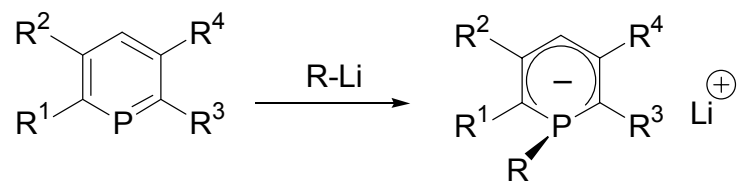

19

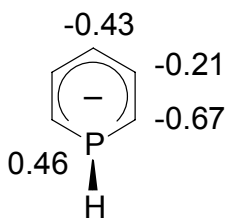

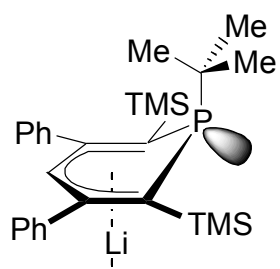

$\mathrm{Et}^{-} \mathrm{O}_{\mathrm{Et}}$

$\overbrace{-0.69}^{-0.49}$

\section{Scheme 9}

Reactions of these anions with transition metal precursors clearly depend on both the nature of the metal fragment and the substitution scheme of the ring. Whereas $\left[\mathrm{ML}_{\mathrm{n}} \mathrm{X}\right]$ metal fragments react with anions to yield $\pi$-complexes such as the rhodium derivative 21,[25] reaction with $\left[\mathrm{ML}_{\mathrm{n}} \mathrm{X}_{2}\right]$ metal fragments (group 10 metals) yield $\eta^{2}$-complexes such as $\mathbf{2 2}$ in which coordination occurs through the P-C bond (Scheme 10).[26] The solid state structure of 22 is not wholly retained in solution. Dynamic behavior of the $\left[\mathrm{M}\left(\mathrm{PPh}_{3}\right) \mathrm{Cl}\right](\mathrm{M}=\mathrm{Pd}, \mathrm{Pt})$ 
fragment is apparent from the systematic changes observed in the variable temperature ${ }^{1} \mathrm{H}$ NMR data. DFT calculations on model complexes were performed to determine the structure of the transition state $\mathbf{2 3}$ in the case of the palladium complex. As can be seen in scheme 10, this transition state involves a $\eta^{1}$-coordination of the $\left[\mathrm{Pd}\left(\mathrm{PPh}_{3}\right) \mathrm{Cl}\right]$ fragment onto the phosphorus atom, the interconversion between the two enantiomeric complexes resulting from a simple rotation of the fragment (or the ligand) around the Pd-P bond axis in 23. A good agreement was found between theoretical $\left(30.2 \mathrm{~kJ} \mathrm{~mol}^{-1}\right)$ experimental $\left(43.7 \mathrm{~kJ} \cdot \mathrm{mol}^{-1}\right) \Delta \mathrm{G}^{\#}$ values.[26]

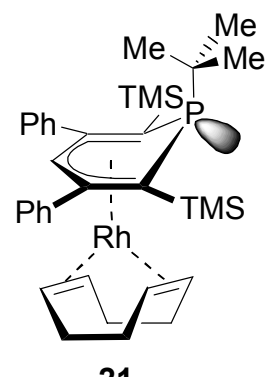

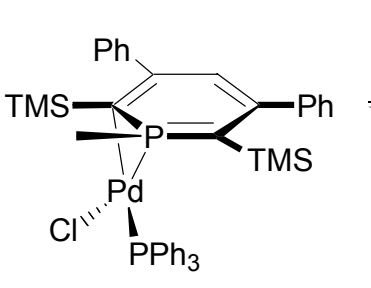

22

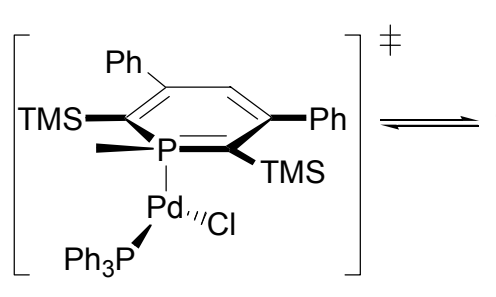

23

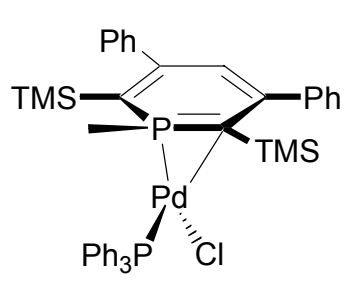

$\mathrm{Ph}_{3} \mathrm{P} " \mathrm{Cl}$

Scheme 10

Interestingly, the presence of ancillary peripheral ligands at the $\alpha$-carbon atoms of the ring was found to be determinant in the synthesis of $\eta^{1}-\mathrm{P}$ coordinated complexes. Thus, reaction of phosphinine $\mathbf{2 4}$ with $n$-BuLi afforded anion 25 which in turn was trapped with $\left[\mathrm{M}(\mathrm{COD}) \mathrm{Cl}_{2}\right](\mathrm{M}=\mathrm{Pd}, \mathrm{Pt})$ to afford the corresponding complexes 26, 27 in which the anion behaves as a tridentate ligand. These group 10 complexes were found to be remarkably resistant toward moisture and air oxidation (Scheme 11).[27-29] 


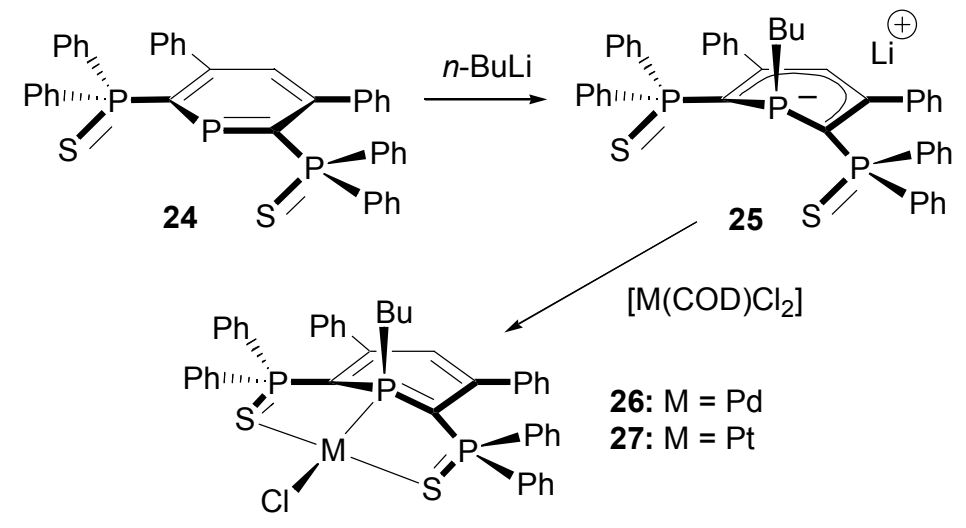

Scheme 11

The preference for $\eta^{1}$-coordination can be easily rationalized by considering a simple perturbation diagram of these phosphacyclohexadienyl anions MOs. In such systems, the HOMO is a $\pi$-orbital featuring important coefficient on the $\mathrm{C}_{\alpha}$ and $\mathrm{C}_{\gamma}$ carbon atom and the HOMO-1 mainly describes the lone pair at phosphorus. Introduction of two ancillary groups possessing lone pairs result in a combination of these two orbitals with the in-phase combination of the two lone pairs. This results in a repulsive interaction that strongly destabilizes the HOMO-1 (more important overlap). Therefore, in such tridentate SPS anionic ligands, the HOMO features an important contribution of the lone pair at phosphorus as well as a significant participation of the two lone pairs at the ligand this favoring $\sigma$-coordination at phosphorus (Scheme 12).

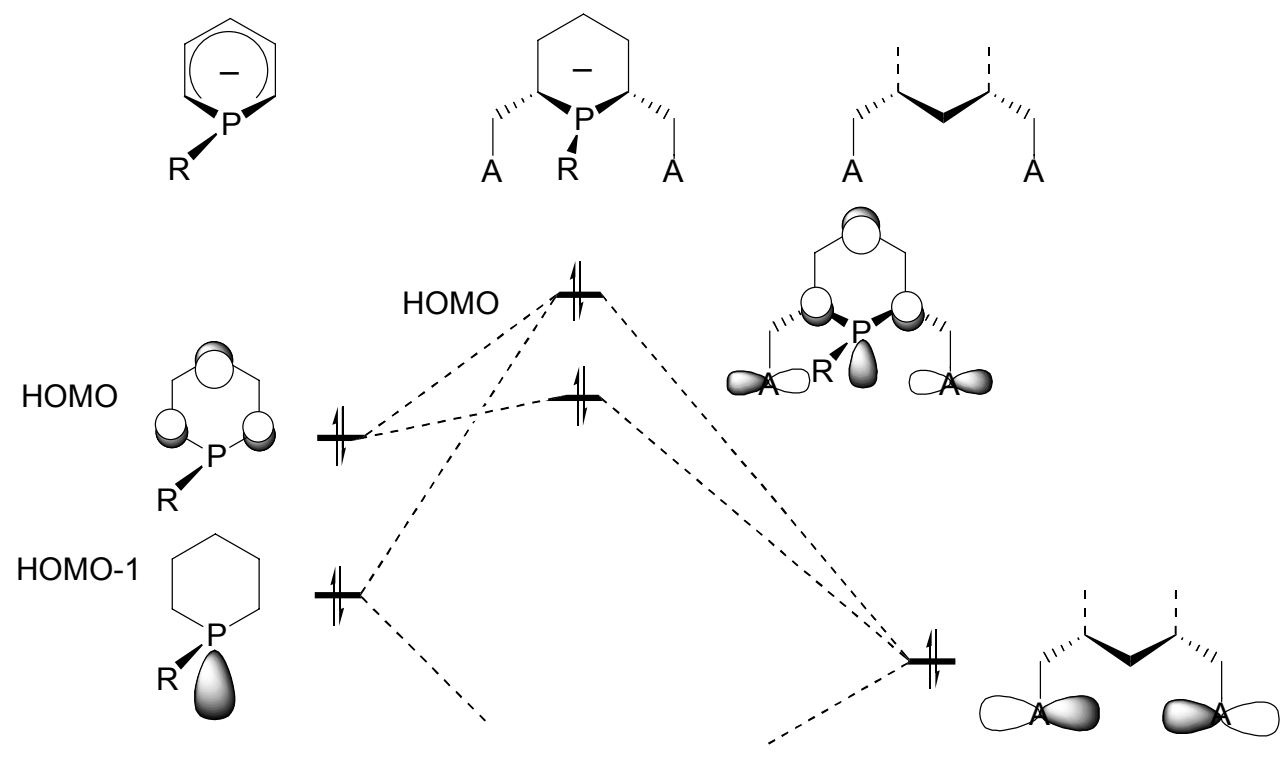


Further studies showed that other synthetic strategies could be employed to synthesize group 10 square planar complexes. Thus, reaction of phosphinine $\mathbf{2 4}$ with $\left[\mathrm{Pd}(\mathrm{COD}) \mathrm{Cl}_{2}\right]$ affords the chloro-P chloropalladium complex $\mathbf{2 8}$ which can in turn be functionalized at phosphorus through nucleophilic substitution.[27] Another interesting method involves the oxidative addition of a $\mathrm{P}-\mathrm{Cl}$ bond of a $\lambda^{5}$-P-dichloro-phosphinine 29 onto a $\mathrm{Pd}(0)$ fragment to give complex 30.[28] Most surprisingly, even P-oxide derivatives of 1,2-dihydrophosphinines such as $\mathbf{3 1}$ proved to be valuable precursors of tridentate SPS-based complexes such as 32 featuring a central P-OH group as ligand (Scheme 13).

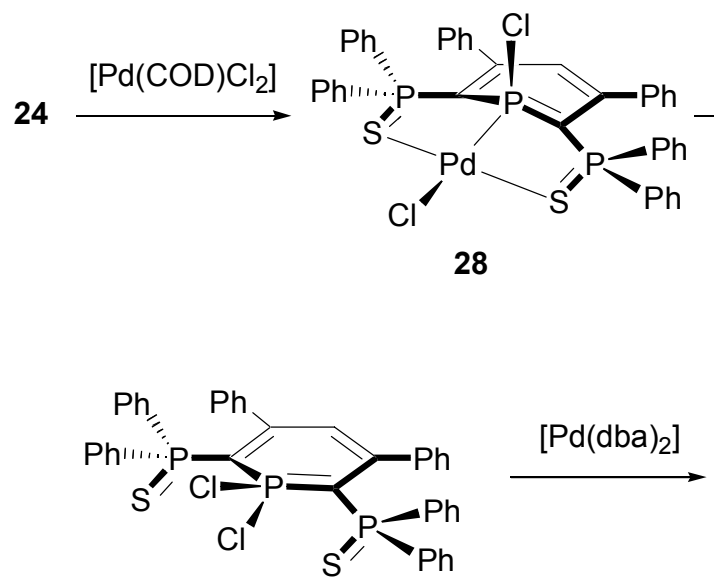

29

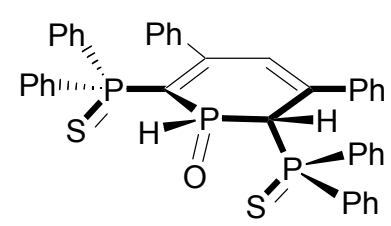

31

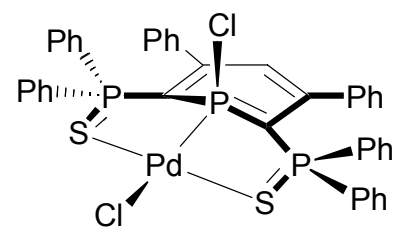

30

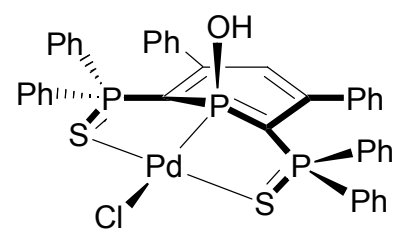

32

Scheme 13

All these $\sigma$-complexes can be regarded either as a $\lambda^{5}$-metallated phosphinine (form I) or as a classical $\sigma$-complex of a phosphacyclohexadienyl anion (form II). Though both forms very likely contribute in the bonding, preliminary calculations suggest that form II is probably predominant (Scheme 14). DFT calculations and charge decomposition analysis (CDA) suggest that a delocalization takes place within the carbocyclic part of the ligand and that the central phosphorus atom behaves as a classical tertiary phosphorus atom.[28] 
<smiles>CP(C1=CC(c2ccccc2)=C(P(=S)(c2ccccc2)c2ccccc2)P1(C)=S)c1ccccc1</smiles>

form I<smiles>CP1C(P)=CC(c2ccccc2)=C(P(=S)(c2ccccc2)c2ccccc2)P1C(=S)Pc1ccccc1</smiles>

form II

\section{Scheme 14}

Other sigma complexes were prepared according to the same synthetic strategy. The most significant results were obtained in studying the chemistry of group 9 metals. Thus, reaction of anion 33 with the $[\mathrm{Rh}(\mathrm{COD}) \mathrm{Cl}]_{2}$ dimer yielded the very stable 18 electron complex 34 whose structure remains unknown. However, displacement of the COD ligand from 34 afforded the highly reactive square planar 16 electron complex 35 which was structurally characterized. Complex 35 proved to be highly reactive toward small molecules such as $\mathrm{O}_{2}, \mathrm{CO}_{2}, \mathrm{CS}_{2}$ and $\mathrm{SO}_{2}$. Whereas reaction with $\mathrm{O}_{2}, \mathrm{CO}_{2}$ and $\mathrm{CS}_{2}$ yielded trigonal bipyramidal $\mathrm{Rh}(\mathrm{III})$ complexes in which the SPS ligand caps one face of the bipyramid such as in the $\eta^{2}-\mathrm{O}_{2}$ complex 36, reaction with $\mathrm{SO}_{2}$ afforded a $\mathrm{Rh}(\mathrm{I})$ complex 37 which adopts a pyramidal geometry. Interestingly, in all cases, attack of the incoming ligand has taken place on the syn face of the complex (Scheme 15).[30] Calculations are currently underway in our laboratories to determine the origin of this facial discrimination.
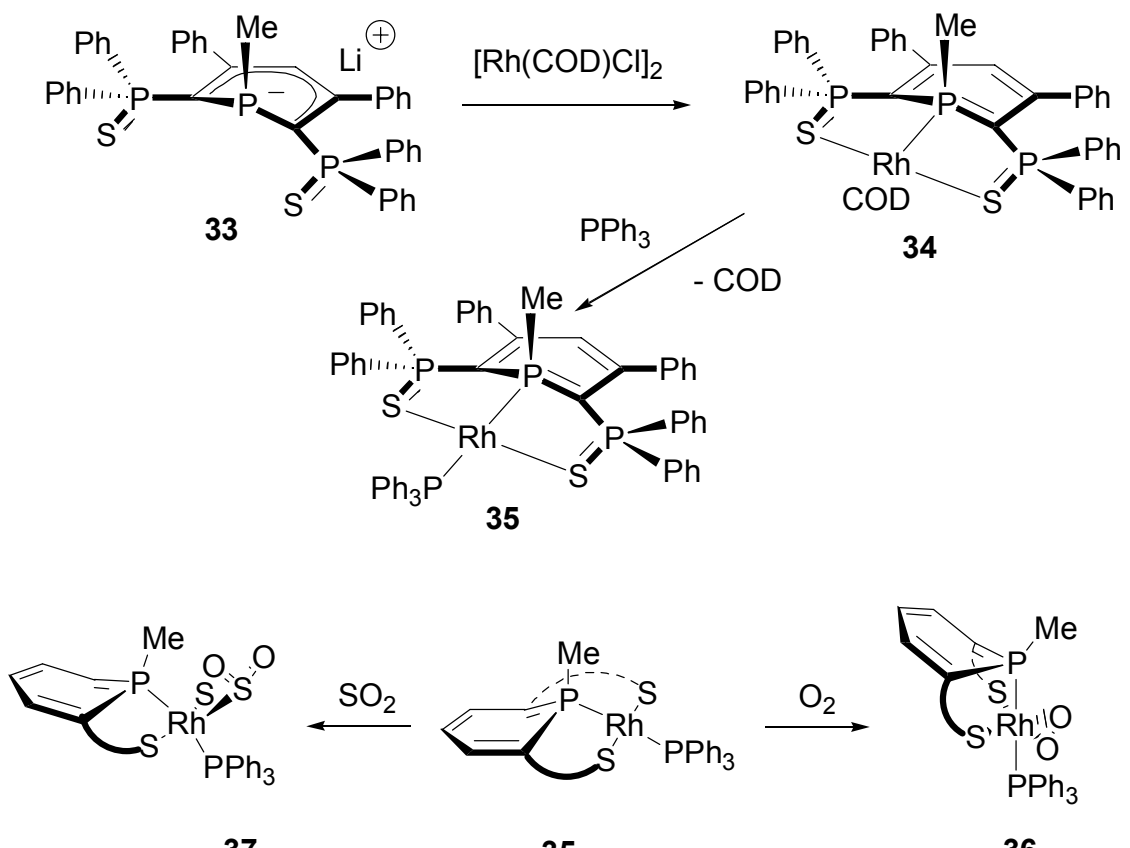

Scheme 15 
II.2) Mixed SP and SPS ligands and their complexes in catalysis.

The flexibility of the SPS ligand was also evidenced in a recent study dealing with the coordination chemistry of $\mathrm{Cu}(\mathrm{I})$ and $\mathrm{Au}(\mathrm{I})$ derivatives. An insoluble oligomeric copper complex 38 was obtained by reacting the anionic ligand 34 with $\mathrm{CuI}$ in $\mathrm{THF}$ at room temperature. Reaction of $\mathbf{3 8}$ with two electron-donor ligands such as 2,6dimethylphenylisocyanide, $t$-butylisocyanide, $\mathrm{PPh}_{3}, \mathrm{P}(\mathrm{OPh})_{3}$ and pyridine afforded the expected tetrahedral $\mathrm{Cu}(\mathrm{I})$ complexes 39 in which the ligand caps three binding sites (Scheme 16).[31]

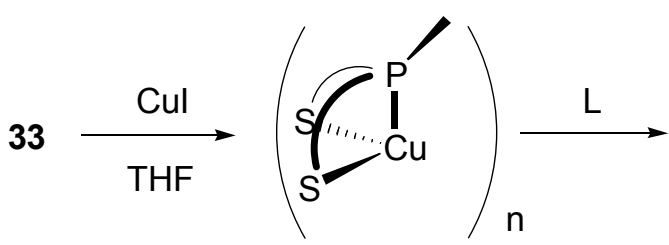

38

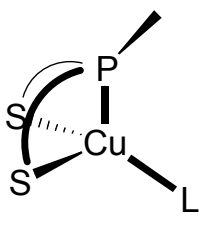

39

\section{Scheme 16}

The catalytic activity of palladium (II) complexes of these SPS ligands was tested in different processes. In the Heck-coupling between methyl-acrylate and iodobenzene, methyl trans-cinnamate was produced in a quantitative yield with a TON of 10000 . A quite promising result was obtained in the Miyaura cross-coupling reaction which allows the formation of boronic esters from halogenoarenes and pinacolborane.[27] Whereas no reaction was observed with arylchlorides, catalyst $\mathbf{2 6}$ proved to be sufficiently reactive to convert iodo and bromo derivatives in dioxane at reflux in good yields. With aryliodides TON up to 76500 were recorded (Scheme 17).

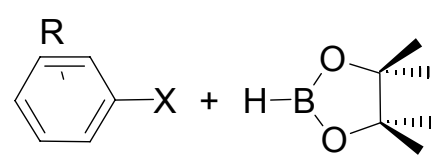

$\mathrm{X}=\mathrm{Br}, \mathrm{I}$

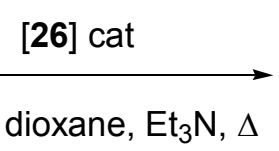

dioxane, $\mathrm{Et}_{3} \mathrm{~N}, \Delta$

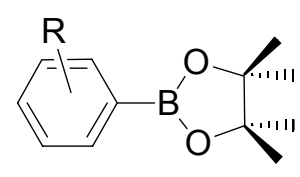

TON up to 76500

\section{Scheme 17}

Importantly, we recently found that bidentate PS ligands could also be produced in a similar way by reacting alkyllithium derivatives with phosphinine 40. Here again, coordination occurs through the phosphorus atom lone pair the sulfur ligand serving as a second binding site. $\mathrm{Ru}(\mathrm{II})$ cymene 41 and the $\mathrm{Pd}(\mathrm{II})$ allyl 42 complexes were easily produced 
and characterized by X-ray crystallography. Though the ruthenium complex exhibited a moderate activity in the transfer hydrogenation of ketones using isopropanol as a proton source, complex 42 showed an interesting activity in the Suzuki coupling process that furnishes functional biphenyl derivatives through the reaction of phenylboronic acid with bromoarenes (TON up to 799000 with 4-bromoacetophenone as substrate) (Scheme 18).

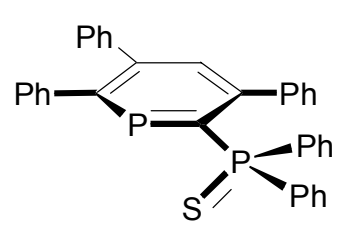

40
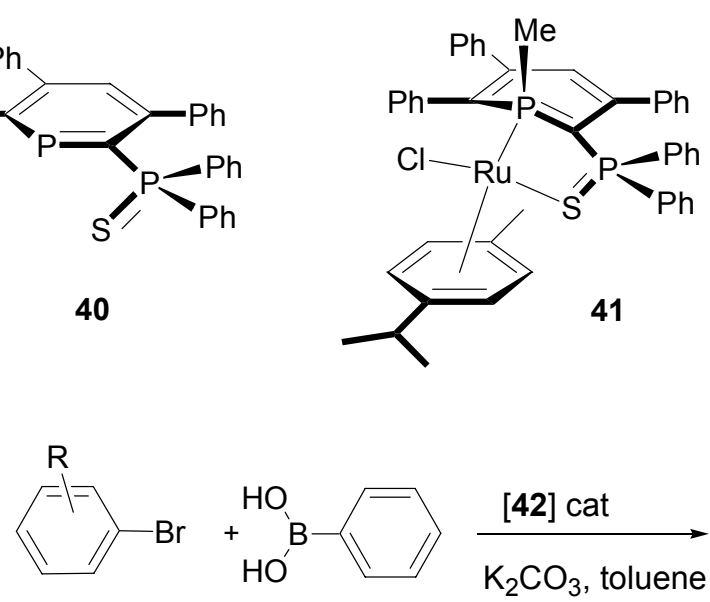

$\Delta, 24 \mathrm{~h}$
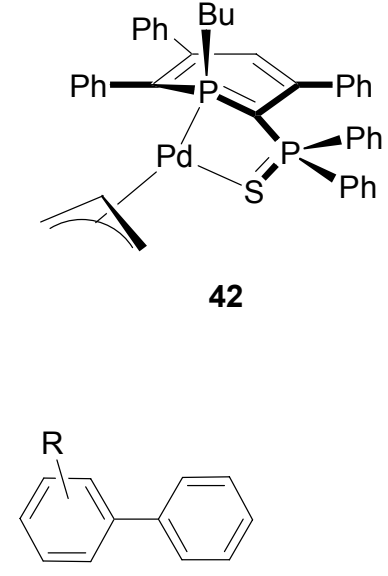

TON up to $79910^{3}$

\section{Scheme 18}

In conclusion, it appears that, despite their high sensitivity which usually precludes their use as ligands in catalysis, phosphinines proved to be a valuable source of new heterocyclic ligands and complexes. Further studies will now focus on the systematic study of the binding properties of these new bidentate SP and tridentate SPS ligands in coordination chemistry and catalysis.

Acknowledgments: The authors thank the CNR and the Ecole Polytechnique for the financial support of this work. 


\section{References:}

[1] see for example: F. Mathey, Angew; Chem. Int. 42 (2003) 1578.

[2] a) P. Le Floch, A. Marinetti, L. Ricard, F. Mathey, J. Am. Chem. Soc. 112 (1990) 2407. b) P. Le Floch, F. Mathey, Synlett, (1990) 171. c) A. Marinetti, F. Mathey, Angew. Chem. 100 (1988) 1435. c) A. Marinetti, S. Bauer, L. Ricard, F. Mathey, Organometallics 9 (1990) 793. d) A. Marinetti, P. Le Floch, F. Mathey, Organometallics 10 (1991) 1190. e) S. Shah, J. D. Prostaziewicz, Coord. Chem. Rev. 210 (2000) 181. f) S. Shah, J. D. Prostaziewicz, Chem. Commun. (1998) 1585. g) S. Shah, T. Concolino, A. L. Rheingold, J. D. Prostaziewicz, Inorg. Chem. 39 (2000) 3860 .

[3] a) F. Mathey, J. Organomet. Chem., 93 (1975) 377. b) F. Mathey, Tetrahedron Lett., 17 (1976) 4155. c) F. Mathey, A. Mitschler, R. Weiss, J. Am. Chem. Soc., 100 (1978) 5748. d) G. de Lonzon, F. Mathey, M. Simalty, J. Organomet. Chem., 156 (1978) C33. e) G. de Lonzon, B. Deschamps, J. Fischer, F. Mathey, J. Am. Chem. Soc., 102 (1980) 994.

[4] K. B. Dillon, F. Mathey, J. F. Nixon, Phosphorus: The carbon Copy, Wiley, Chichester (1988)

[5] C. Elschenbroich, M. Nowotny, A. Behrendt, W. Massa, S. Wocaldo, Angew. Chem. Int. Ed. Engl. 31 (1992) 1343.

[6] C. Elschenbroich, M. Nowotny, J. Kroker, A. Behrendt, W. Massa, S. Wocaldo, J. Organomet. Chem. 459 (1993) 157

[7] C. Elschenbroich, S. Voss, O. Schiemann, A. Lippek, K. Harms, Organometallics 17 (1993) 4417.

[8] N. Mézailles, F. Mathey, P. Le Floch, Prog. Inorg. Chem. 49 (2001) 455.

[9] a) P. Le Floch, D. Carmichael, L. Ricard, F. Mathey, J. Am. Chem. Soc. 113 (1991) 667. b) P. Rosa, N. Mézailles, L. Ricard, F. Mathey, P. Le Floch, J. Org. Chem. 63 (1998) 4826.

[10] P. Rosa, N. Mézailles, L. Ricard, F. Mathey, P. Le Floch, Angew. Chem. Int. Ed. 39 (2000) 1823.

[11] F. Hartl, T. Mahabiersing, P. Rosa, L. Ricard, P. Le Floch, Inorg. Chem. 42 (2003) 4442. 
[12] P. Rosa, N. Mézailles, L. Ricard, F. Mathey, P. Le Floch, Y. Jean, Angew. Chem. Int. Ed. Engl. 40, 2001, 1251.

[13] N. Mézailles, P. Rosa, L ; Ricard, F. Mathey, P. Le Floch, Orgnaometallics, 19 (2000) 2941.

[14] S. Choua, H. Sidorenkova, T. Berclaz, M. Geoffroy, P. Rosa, N. Mézailles, L. Ricard, F. Mathey, P. Le Floch, J. Am. Chem. Soc. 122 (2000) 12227.

[15] a) P. Rosa, L. Ricard, F. Mathey, P. Le Floch, Organometallics, 18 (1999) 348. b) P. Rosa, N. Mézailles, L. Ricard, F. Mathey, P. Le Floch, Angew. Chem. Int. Ed. Engl. 40 (2001) 4476.

[16] H. Perron, A. Moores, I. Demachy, A. Lledos, Y. Jean, P. Le Floch, New. J. Chem. (2004) in press.

[17] N. Mézailles, N. Avarvari, N. Maigrot, L. Ricard, F. Mathey, P. Le Floch, L. Cataldo, T. Berclaz, M. Geoffroy, Angew. Chem. Int. Ed. 38 (1999) 3194.

[18] a) N. Avarvari, N. Mézailles, L. Ricard, P. Le Floch, F. Mathey, Science, 8 (1998) 1587. b) L. Cataldo, S. Choua, T. Berclaz, M. Geoffroy, J. Phys. Chem. A 106 (2002) 3017.

[19] a) T. Minami, H. Okamoto, S. Ikeda, R. Tanaka, F. Ozawa, M. Yoshifuji, Angew. Chem.-Int. Edit. 40 (2001) 4501. b) F. Ozawa, H. Okamoto, S. Kawagishi, S. Yamamoto, T. Minami, M. Yoshifuji, J. Am. Chem. Soc.124 (2002) 10968.c) M. Yoshifuji, J. Syn. Org. Chem. Jpn. 61 (2003) 1116.

[20] a) X. Sava, L. Ricard, F. Mathey, P. Le Floch, Organometallics 19 (2000) 4899. b) R. Shintani, M.M.C. Lo, G.C. Fu, Org. Lett. 2 (2000) 3695. c) M. Ogasawara, K. Yoshida, T. Hayashi, Organometallics 20 (2001) 3913. d) K. Tanaka, G.C. Fu, J. Org. Chem. 66 (2001) 8177. e) R. Shintani, G.C. Fu, Org. Lett. 4 (2002) 3699. f) D. Carmichael, J. Klankermayer, L. Ricard, N. Seeboth, Chem. Commun. 9 (2004) 1144.

[21] a) B. Breit, R. Winde, T. Mackewitz, R. Paciello, K. Harms, Chem.-Eur. J. 7 (2001) 3106. b) B. Breit, R. Winde, K. Harms, J. Chem. Soc.-Perkin Trans. 1 (1997), 2681.

[22] F. Knoch, F. Kremer, U. Schmidt, U. Zenneck, P. Le Floch, F. Mathey, Organometallics, 15 (1996) 2713.

[23] D. Carmichael, P. Le Floch, F. Mathey, unpublished results.

[24] A. Moores, L. Ricard, P. Le Floch, N. Mézailles, Organometallics 22 (2003) 1960.

[25] A. Moores, N. Mézailles, L. Ricard, P. Le Floch, submitted.

[26] Moores, N. Mézailles, L. Ricard, Y. Jean, P. Le Floch, Organometallics 23 (2004) 2870. 
[27] M. Doux, N. Mézailles, M. Melaimi, L. Ricard, P. Le Floch, Chem. Commun. (2002) 1566.

[28] M. Doux, N. Mézailles, L. Ricard, P. Le Floch, Eur. J. Inorg. Chem. (2003) 3878.

[29] M. Doux, C. Bouet, N. Mézailles, L. Ricard, P. Le Floch, Organometallics 21(2002)2785.

[30] M. Doux, N. Mézailles, L. Ricard, P. Le Floch, Organometallics 22 (2003) 4624.

[31] M. Doux, L. Ricard, P. Le Floch, N. Mézailles, Dalton Trans (2003) in press.

[32] M. Dochnahl, M. Doux, E. Faillard, L. Ricard, P. Le Floch, submitted. 